\title{
Design and Analysis of a Kaplan Turbine Runner Wheel
}

\author{
Chamil Abeykoon ${ }^{1}$, Tobi Hantsch ${ }^{2}$ \\ ${ }^{1}$ Faculty of Science and Engineering, University of Manchester \\ Oxford Road, M13 9PL, Manchester, UK \\ chamil.abeykoon@manchester.ac.uk \\ ${ }^{2}$ Devison of Applied Science, Computing and Engineering, Glyndwr University \\ Mold Road, LL11 2AW, Wrexham, UK
}

\begin{abstract}
The demand for renewable energy sources such as hydro, solar and wind has been rapidly growing over the last few decades due to the increasing environmental issues and the predicted scarcity of fossil fuels. Among the renewable energy sources, hydropower generation is one of the primary sources which date back to 1770s. Hydropower turbines are in two types as impulse and reaction where Kaplan turbine is a reaction type which was invented in 1913. The efficiency of a turbine is highly influenced by its runner wheel and this work aims to study the design of a Kaplan turbine runner wheel. First, a theoretical design was performed for determining the main characteristics where it showed an efficiency of $94 \%$. Usually, theoretical equations are generalized and simplified and also they assumed constants of experienced data and hence a theoretical design will only be an approximate. This was confirmed as the same theoretical design showed only 59.98\% of efficiency with a computational fluids dynamics (CFD) evaluation. Then, the theoretically proposed design was further analysed where pressure distribution and inlet/outlet tangential velocities of the blades were analysed and corrected with CFD to improve the efficiency of power generation. The original design could be improved to achieve an efficiency of $93.01 \%$. In general, the blades' inlet/outlet angles showed a significant influence on the turbine's power output. Finally, a comparison of the optimised and theoretical design is presented.
\end{abstract}

Keywords: Hydropower; Turbine; Power output; Blade angle; Modelling; Optimization; CFD

\section{Introduction}

Currently, harmful emissions and greenhouse gases are causing serious climate changes and a huge environmental pollution all over the world. Hence, scientists are desperately researching for possible green alternatives to replace the widely used fossil fuels where renewable energy sources would be their key priority. Although the use of renewable energies would not solve the problems over night, it would be the best move to solve the prevalent issues in the long-run.

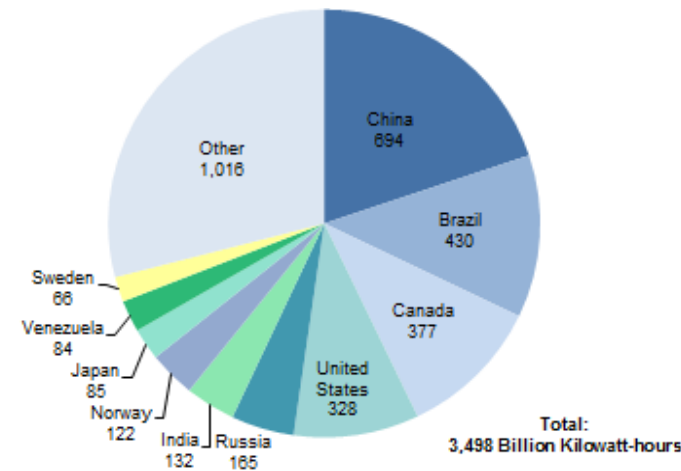

Fig. 1: Hydropower generation in year 2011 (Billion $\mathrm{kWh}$ ) [1]. 


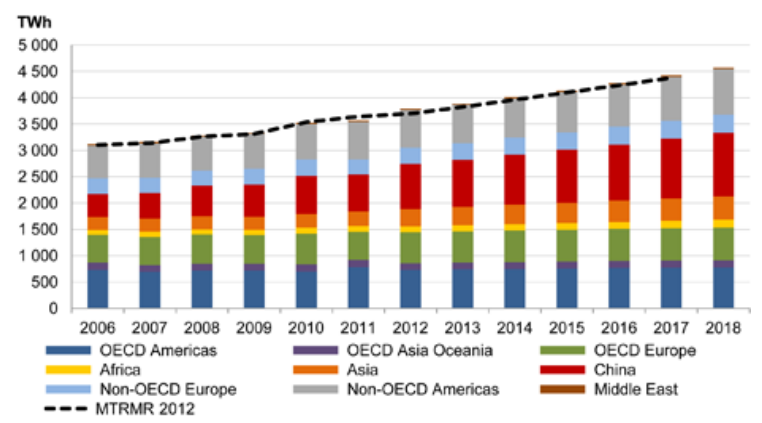

Fig. 2: Hydropower and other renewable electricity generation, 1990-2010 (in terawatt-hours, TWh) [2].

Under these circumstances, renewable energy sources such as hydro, solar, wind, geothermal, wave and tidal current have been the current major focus of the global energy sector. Hydropower is the largest (at its current state), the oldest and the most reliable source of renewable energy generation. In 2010, hydro power generation accounts $16.3 \%$ (about 3500 $\mathrm{TWh}$ ) from the global electricity generation and some of the relevant facts are shown in Figures 1 and 2. Wind turbines work only when wind is blowing, Solar panels perform well only when the sun is shining but water is quite constantly flowing in the rivers [2,3]. Hence, hydropower plants can be found all over the world and their turbines can have efficiencies of up to $95 \%$, an average power generation capacity of up to 800 MW (theoretically) and heads of up to 1.8 $\mathrm{km}$, depending on the model type [4]. The world's largest hydropower plant is the Three Gorges Dam in China with a generating capacity of 22,500 MW which was completed in 2012 with 32 turbines [5]. The design of the runner blades is crucial for an efficient turbine. The blades extract the energy of the flowing water and converts into rotational energy and then to electrical energy. Therefore, the blade design must be optimized to extract as much energy as possible to achieve the highest possible efficiency but is also endangered for cavitation. Hence, it is timely important to further study on hydropower turbines for improving their power generation capacity/efficiency $[4,6]$.

\subsection{History of hydropower generation}

The Greeks are known as the first who used hydropower in 2000 years ago. As reported, they have built water wheels for grinding wheat into flour, sawing wood and also to power textile mills. Then, in mid 1700s, the evolution of the modern hydropower turbines began when B. F. de Bèlidor, a French hydraulic and military engineer, wrote "Architecture Hydraulique" which was a four volume report describing vertical and horizontal axis machines. Later in 1880, the Michigan's Grand Rapids Electric Light \& Power Company generated the hydro-electricity for the first time by a dynamo connected to a water turbine to light up 16 lamps in their theatres and stores. The world's first hydroelectric power plant was built on the Fox River in Appleton, Wisconsin in 1882 with an output power of $12.5 \mathrm{Kw}$. About 33 years later in August 1913, the Kaplan-Turbine, as it is known today, was invented by Viktor Kaplan in Austria [3, 7].

\subsection{Turbines in hydropower}

Hydropower plants can be equipped with different types of turbines depending on the head and discharge of the site to reach the highest possible efficiency. These turbines can be divided into three major types: Francis, Kaplan and Pelton turbines as shown in Figure 3 and also they can be classified as reaction and impulse types. Figure 3 shows the application areas of turbines depending on the head $(H)$ and a dimensionless coefficient relating to specific speed $(\sigma)$. 


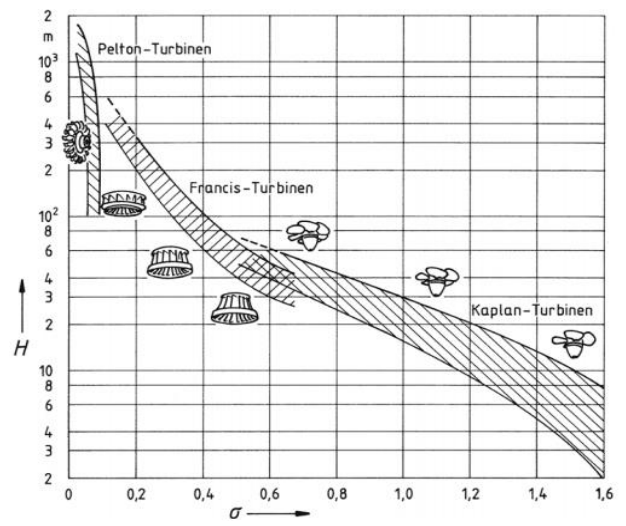

Fig. 3: The use of turbines with varying head [4].

The head $H$ is difference between headwater and tailwater. As shown in Fig. 3, Pelton turbines are used for high heads while Francis and Kaplan turbines are used for medium and low heads, respectively. $\sigma$ is a characteristic factor which depends on the wheel's rotational speed $(N)$, volumetric flow rate $(\dot{V})$ and acceleration due to the gravity $(g)$, and it is given in Eq. (1).

$$
\sigma=\frac{2 N \sqrt{\pi \dot{V}}}{(2 g H)^{3 / 4}}
$$

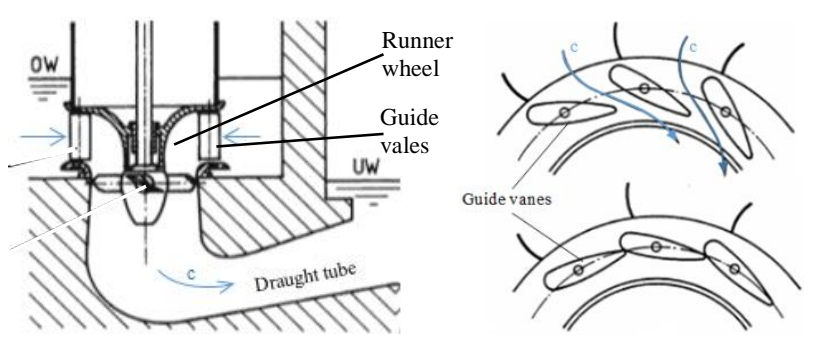

Fig. 4: A Kaplan turbine (runner wheel and guide vanes).

The Kaplan turbine is a reaction type which is suitable for low pressure hydropower plants and can be used with big discharges. The Kaplan runner, similar to the Francis runner, also should be submerged in the water for proper operation. The water enters to the runner through regulated guide vanes which are radially mounted around the turbine inlet and hits with a certain angle of attack on the runner blades as shown in Figure 4. To achieve the highest possible efficiency at varying flow rates, the guide vanes and runner blades are adjustable and can be regulated by a controller. At a constant flow rate static blades are sufficient. The guide vanes can also be shut in case of a problem to protect the runner. As the water hits the blades it transmits its energy to the blades and streams out through the draught tube. The runner can be positioned vertically as shown in Figure 4, otherwise horizontally or somewhere in between. If the cross section of the draught tube is assumed to be constant, the velocity does not vary from the inlet to outlet due to the continuity. Static pressure changes at the suction head does not affect the efficiency and hence the runner could be placed anywhere in the draught tube. When the runner is placed inside the tube, the guide vanes must be placed just in front of the runner for producing an accurate twist. But if the draught tube is quiet long, the risk of cavitation increases due to a high head $[4,8]$.

\subsection{Previous work on Kaplan turbine design and optimization}

Previous study by Bashir et al. [9] investigated the experimental and CFD predicted power outputs of a Kaplan turbine. The both results were quite similar where CFD results showed slightly less values to the experimental values in most of the flow rates. Another work by Dragica et al. [10] analysed the discrepancy between numerical simulations (also 
known as CFD) and experimental measurements of a Kaplan turbine to find out how accurate the numerical methods really are. They observed several aspects such as Steady state simulations, Curvature Correction, Kato-Launder, Shear-stresstransport, Scale-adaptive-simulation and Zonal Large-eddy-simulation. Steady state simulations with various turbulence models turned out to be the most inaccurate method by showing considerable errors of full discharge rate. The best results were made by Scale-adaptive-simulation, Shear-stress-transport and Zonal Large-eddy-simulation with less than $1 \%$ of discrepancy to the real measurements.

\section{Case study details}

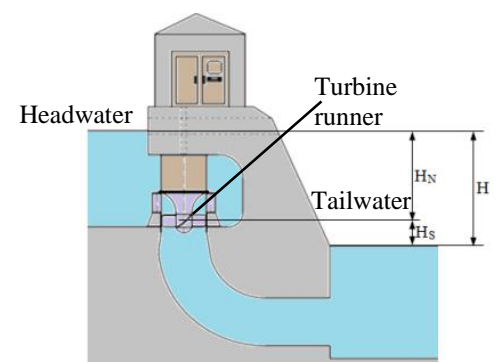

Fig. 5: Details of the case study.

In this work, a theoretical design of a Kaplan runner wheel is presented. Then, the theoretically proposed design is further analysed with CFD to achieve the optimum performance. The ultimate aim is to achieve the highest possible power output by optimizing the turbine blades. A case study is considered where a Kaplan turbine is assumed to be inside a dam of a river-based hydropower plant as shown in Figure 5. The head $(H)$ of $6 \mathrm{~m}$ and a constant volumetric flow rate $\dot{V}$ of $5 \mathrm{~m}^{3} \cdot \mathrm{s}^{-1}$ are considered. Net head $H_{N}$ and suction head $H_{S}$ are defined across the middle plane of the turbine runner to headwater and tailwater, as presented in Figure 5. The value of $\sigma$ is taken as 1.45 and which can be read out from Figure 3.

\section{Theoretical design}

Procedures followed in the theoretical design process are discussed in the followings.

\subsection{Flow parameters}

The rotational speed $N$ of the turbine is given by Eq. 2 [4]:

$$
N=\frac{\sigma(2 g H)^{3 / 4}}{2 \sqrt{\pi \dot{V}}} \frac{1.45(2 \times 9.81 \times 6)^{3 / 4}}{2 \sqrt{\pi 5}}=6.538 \mathrm{~s}^{-1}=392.28 \mathrm{~min}^{-1}
$$

Then, the specific speed is obtained form Eq. (3):

$$
N_{S}=\frac{n \sqrt{\dot{V}}}{H^{3 / 4}}=\frac{6.538 \sqrt{5}}{6^{3 / 4}}=228.78
$$

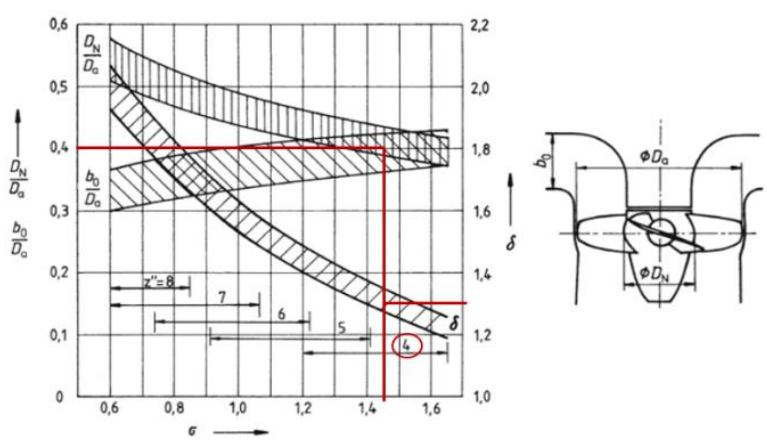

Fig. 6: Design diagram for a Kaplan turbine [4]. 
Figure 6 illustartes the relationship between hub (inner) and outer diameters of the wheel $\left(D_{a}, D_{N}\right), \sigma$, diameter number $(\delta)$, ratio of $\left(D_{N} / D_{a}\right)$ and number of blades $\left(z^{\prime \prime}\right)$. The outer diameter of the runner can be defined with Eq. (4):

$$
D_{a}=\frac{2 \delta}{\sqrt{\pi}} \times \sqrt[4]{\frac{\dot{V}^{2}}{2 g H}}=\frac{2 \times 1.3}{\sqrt{\pi}} \times \sqrt[4]{\frac{5^{2}}{2 \times 9.81 \times 6}}=0.996 \mathrm{~m}
$$

The diameter number $(\delta)$ of 1.3 is related to $\sigma=1.45$ and diameter ratio $\left(D_{N} / D_{a}\right)$ of 0.4 . Thus, the hub diameter $\left(D_{N}\right)$ can be calculated as below:

$$
D_{N}=D_{a} \times 0.4=0.996 \times 0.4=0.398 m
$$

The number of blades $\left(z^{\prime \prime}\right)$ are related to $\sigma$ and can be read out from Figure 6 . The suction head $\left(H_{S m a x}\right)$ is defined by Eq. (6):

$$
\begin{gathered}
H_{\text {Smax }}=\frac{p_{a t m}}{\rho g}-\frac{p_{v}}{\rho g}-\sigma_{c} H \\
H_{\text {Smax }}=\frac{101300}{999 \times 9.81}-\frac{1279}{999 \times 9.81}-1.3 \times 6=2.396 \mathrm{~m}
\end{gathered}
$$

Where $p_{a t m}$ is the atmospheric pressure, $p_{v}$ is the vapour pressure of water, $\sigma_{c}$ is the cavitation coefficient, and $\rho$ is the density of the water. For this work, the water temperature and vapour pressure were chosen as $15{ }^{\circ} \mathrm{C}$ and $1279 \mathrm{~Pa}$, respectively. Usually, $\sigma_{c}$ is obtained by the turbine manufacturer through model testing [11]. A maximum suction head $\left(H_{\text {Smax }}\right)$ of $2.396 \mathrm{~m}$ was given by Eq. (6) as the maximum possible head to avoid cavitation and hence the suction head $\left(H_{S}\right)$ of $2 \mathrm{~m}$ was chosen for the case study.

\subsection{Turbine blade design}

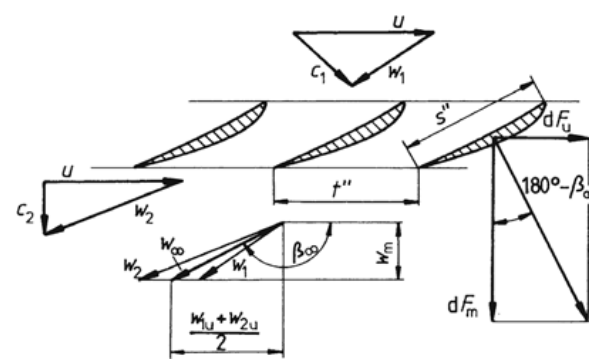

Fig. 7: Schematic of blades' cross sections and relevant velocity triangles [4].

Non-adjustable identical blades were considered for this work due to the constant discharge. Hence, the blades can be permanently fixed to the hub as they no need to be adjusted. To define the shape of the blades theoretically, velocity triangles were considered at the leading and trailing edges and also in the middle of the blade at 5 different diameters $\left(D_{N}\right.$, $\left.D_{1}, D_{2}, D_{3}, D_{4}, D_{a}\right)$ as shown in Figure 8. Altogether, 15 velocity triangles were considered for each blade. Figure 7 shows the sectional views at a certain diameter of 3 blades in a straight plane where 1,2 and $\infty$ represent the velocities at the inlet, outlet and middle of the section, respectively. Here, $c$ is the velocity of the fluid flow, $w$ is the relative velocity, and $u$ is the tangential velocity. The meridian relative velocity $w_{m}$ establishs its own triangle with the average of $w_{1}$ and $w_{2}$ and the angle $\beta_{\infty}$. The chord length is given by $s$ " and the distance between the blades by $t$ " which also depends on the wheel diameter $[4,12]$. Each blade section at different radii will have different velocities, angles and chord shapes. The relevant calculations are presented below for the velocity triangle at the middle of the blade on the outer diameter $D_{a}$. The tangential velocity of the balde $(u)$ can be given by Eq. (7): 


$$
u=\pi D n=\pi \times 0.996 \times 6.538=20.452 m . s^{-1}
$$

The relative velocity in meridian direction $w_{m}$ depends on the discharge and area of the fluid flow in the runner and this would be the same for whole runner section. Hence, the inlet velocity $w_{0}$ would also be similar to $w_{m}$.

$$
w_{m}=c_{0}=\frac{\dot{V}}{A}=\frac{\dot{V}}{\frac{1}{4} \pi\left(D_{a}{ }^{2}-D_{N}{ }^{2}\right)}=\frac{5}{\frac{1}{4} \pi\left(0.996^{2}-0.398^{2}\right)}=7.643 \mathrm{~m} . \mathrm{s}^{-1}
$$

The tangential velocity of the fluid flow $\left(c_{u \infty}\right)$ depends on the head and blade's tangential velocity, defined by Eq. (9):

$$
c_{u \infty}=\frac{\left(H-H_{S}\right) g}{u}=\frac{(6-2) \times 9.81}{20.452}=1.919 \mathrm{~m} \cdot \mathrm{s}^{-1}
$$

The difference of the tangential velocity $\left(\Delta w_{u}\right)$ depends on the head and tangential velocity of the blades. The efficiency of the runner is assumed to be the highest possible efficiency for Kaplan runners, 94\% [6].

$$
\Delta w_{u}=w_{u 1}-w_{u 2}=\frac{H g \eta_{e}}{u} \quad=\frac{6 \times 9.81 \times 0.94}{20.452}=2.705 \mathrm{~m} \cdot \mathrm{s}^{-1}
$$

Where, $\eta_{e}$ is the efficiency of the runner, $w_{u 1}$ and $w_{u 2}$ are the tangential relative velocities at the leading and trailing edges, respectively. The relative velocity in the tangential direction is defined by Eq. (11):

$$
w_{u \infty}=c_{u \infty}-u=1.919-20.452=-18.533 \mathrm{~m} \cdot \mathrm{s}^{-1}
$$

The relative velocity at the middle of the blade $w_{\infty}$ is:

$$
w_{\infty}=\sqrt{w_{u \infty}^{2}+w_{m}^{2}}=\sqrt{-18.533^{2}+7.643^{2}}=20.047 \text { m.s }-1
$$

The angle at the middle of the blade with horizontal $\left(\beta_{\infty}\right)$ is defined by Eq. (13):

$$
\beta_{\infty}=90^{\circ}-\tan ^{-1}\left(\frac{w_{u \infty}}{w_{m}}\right)=90^{\circ}-\tan ^{-1}\left(\frac{-18.533}{7.643}\right)=157.589^{\circ}
$$

Usually, the runners over $\sigma=1.3$ is considered as fast runners and hence the runner in this work is a fast runner as $\sigma=1.45$. The runner considered in this work has $s^{\prime \prime} / t^{\prime \prime}$ ratios of 0.75 and 1.3 in the outer and inner diameters, respectively. Then the blade partition $t$ " can be calculated from Eq. (14):

$$
t^{\prime \prime}=\frac{\pi D}{z^{\prime \prime}}=\frac{\pi \times 0.996}{4}=0.782
$$

Thus, the chord length $s^{\prime \prime}$ can be obtained: $s^{\prime \prime}=0.75 t^{\prime \prime}=0.75 \times 0.782=0.587 \mathrm{~m}$

Then, all relevant velocity triangles were calculated with the same principle and the results are presented in Table 1. 
Table 1: Details of the theoretical calculations.

\begin{tabular}{|l|c|c|c|c|c|c|}
\hline & $D_{a}$ & $D_{1}$ & $D_{2}$ & $D_{3}$ & $D_{N}$ & Unit \\
\hline$D$ & 0.996 & 0.846 & 0.697 & 0.548 & 0.398 & {$[\mathrm{~m}]$} \\
\hline$u$ & 20.452 & 17.384 & 14.316 & 11.249 & 8.181 & {$[\mathrm{~m} / \mathrm{s}]$} \\
\hline$c_{u 1}$ & 3.271 & 3.849 & 4.673 & 5.948 & 8.178 & {$[\mathrm{~m} / \mathrm{s}]$} \\
\hline$c_{u 2}$ & 0.566 & 0.666 & 0.809 & 1.029 & 1.415 & {$[\mathrm{~m} / \mathrm{s}]$} \\
\hline$c_{u \infty}$ & 1.919 & 2.257 & 2.741 & 3.488 & 4.797 & {$[\mathrm{~m} / \mathrm{s}]$} \\
\hline$w_{u 1}$ & -17.181 & -13.536 & -9.643 & -5.301 & -0.003 & {$[\mathrm{~m} / \mathrm{s}]$} \\
\hline$w_{u 2}$ & -19.886 & -16.718 & -13.508 & -10.220 & -6.766 & {$[\mathrm{~m} / \mathrm{s}]$} \\
\hline$w_{\infty}$ & 20.047 & 16.948 & 13.871 & 10.892 & 8.359 & {$[\mathrm{~m} / \mathrm{s}]$} \\
\hline$w_{m}$ & 7.643 & 7.643 & 7.643 & 7.643 & 7.643 & {$[\mathrm{~m} / \mathrm{s}]$} \\
\hline$w_{u \infty}$ & -18.533 & -15.127 & -11.576 & -7.760 & -3.384 & {$[\mathrm{~m} / \mathrm{s}]$} \\
\hline$\Delta w_{u}$ & 2.705 & 3.183 & 3.865 & 4.919 & 6.763 & {$[\mathrm{~m} / \mathrm{s}]$} \\
\hline$\beta_{\infty}$ & 157.589 & 153.195 & 146.565 & 135.436 & 113.883 & {$\left[{ }^{\circ}\right]$} \\
\hline$\alpha$ & 23.172 & 26.727 & 31.444 & 37.890 & 46.938 & {$\left[{ }^{\circ}\right]$} \\
\hline$\beta_{1}$ & 156.018 & 150.549 & 141.601 & 124.744 & 90.020 & {$\left[{ }^{\circ}\right]$} \\
\hline$\beta_{2}$ & 158.976 & 155.432 & 150.498 & 143.208 & 131.517 & {$\left[{ }^{\circ}\right]$} \\
\hline$s^{\prime \prime} / t^{\prime \prime}$ & 0.750 & 0.888 & 1.025 & 1.163 & 1.300 & {$[-]$} \\
\hline$t^{\prime \prime}$ & 0.782 & 0.665 & 0.547 & 0.430 & 0.313 & {$[\mathrm{~m}]$} \\
\hline$s^{\prime \prime}$ & 0.587 & 0.590 & 0.561 & 0.500 & 0.407 & {$[\mathrm{~m}]$} \\
\hline
\end{tabular}

The above presented theoretical calculations can be evaluated by checking the expected and resulting efficiency. As was mentioned, the expected efficiency $\eta_{e}$ of the runner was selected as $94 \%$. For a comparison, the resulting efficiency can be calculated with the provided and actual output powers of the runner wheel. The provided power by the water to the runner can be calculated by Eq. (15):

$$
P_{\text {water }}=\rho g H \dot{V}=999 \times 9.81 \times 6 \times 5=294005.7 \mathrm{~W}
$$

By Euler formula given in Eq. (1) and the values of Table 1, the power of the turbine runner wheel can be calculated:

$$
\begin{gathered}
P_{\text {runner }}=\dot{m}\left(u_{1} c_{u 1}-u_{2} c_{u 2}\right)=\dot{m} u \Delta w_{u} \\
\dot{m}=\rho A c_{0}=\delta \frac{1}{4} \pi\left(D_{a}{ }^{2}-D_{N}{ }^{2}\right) c_{0} \\
P_{\text {runner }}=\rho \frac{1}{4} \pi\left(D_{a}{ }^{2}-D_{N}{ }^{2}\right) c_{0} u \Delta w_{u} \\
P_{\text {runner }}=999 \times \frac{1}{4} \pi\left(0,9958^{2}-0.3983^{2}\right) \times 7.64 \times 14.316 \times 3.865 \\
=276365.36 \mathrm{~W}
\end{gathered}
$$

Now the theoritical efficiency is given be:

$$
\eta_{r}=\frac{P_{\text {runner }}}{P_{\text {water }}} \times 100 \%=94 \%
$$

This proves the accurcy of theoritical results and another check will be carried out to compare the theory with CFD. 


\subsection{Coordinate translation}

The velocity triangles itself are not enough to define the shape of the blades. According to the work presented by Bashir et al. [9], a translation of the information from Table 1 into 3D coordinates is necessary for generating a proper 3D model for the CFD analysis. Figure 8 shows the 3D coordinate system of the runner wheel. Red dots represent 15 coordinates describing the blade design which were translated. Table 1 provides the information of the velocity triangle for each of the 15 red dots. Notation 1 describes the coordinates for the blade inlet, $\infty$ for the middle and 2 for the outlet. The following calculations translate the velocities, chord lengths and their angles into Cartesian coordinates. To define the translation of coordinates in y direction, the half arc length of the chord length $s$ " from Table 1 needs to be described by angles $\beta_{\infty}, \beta_{1}$ and $\beta_{2}$ which are shown in Figure 8.

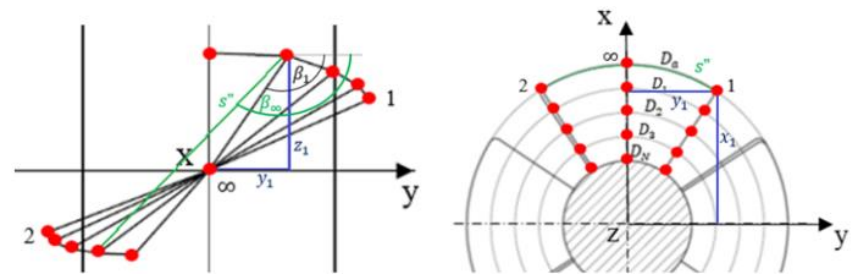

Fig. 8: A schematic of the runner wheel relating to coordinates translation: left - front view, right - top view.

$$
\begin{aligned}
\begin{aligned}
y_{1}=\sin \left(\beta_{1}-90\right) \frac{D \sin \left(\frac{s^{\prime \prime}}{D} \times \frac{180^{\circ}}{\pi}\right)}{2 \cos \left(\beta_{\infty}-\beta_{1}\right)}=\sin (156.018-90) \frac{0.996 \times \sin \left(\frac{0.587}{0.996} \times \frac{180^{\circ}}{\pi}\right)}{2 \times \cos (157.589-156.018)} \\
=253.833 \mathrm{~mm}
\end{aligned} \\
\begin{aligned}
y_{2}=\sin \left(\beta_{2}-90\right) \frac{D \sin \left(\frac{s^{\prime \prime}}{D} \times \frac{180^{\circ}}{\pi}\right)}{2 \cos \left(\beta_{2}-\beta_{\infty}\right)}=\sin (158.976-90) \frac{0.996 \times \sin \left(\frac{0.587}{0.996} \times \frac{180^{\circ}}{\pi}\right)}{2 \times \cos (158.976-157.589)} \\
=-258.280 \mathrm{~mm}
\end{aligned}
\end{aligned}
$$

For defining the coordinates in $\mathrm{z}$ direction, the angle $\beta_{1}$ in $\mathrm{y}$ direction should be established. Hence using tangents, the translation can be defined by Eqs. (21) and (22):

$$
\begin{gathered}
z_{1}=\frac{\mathrm{y}_{1}}{\tan \left(\beta_{1}-90\right)}=\frac{253.833}{\tan (156.018-90)}=112.474 \mathrm{~mm} \\
z_{2}=\frac{\mathrm{y}_{2}}{\tan \left(\beta_{2}-90\right)}=\frac{-258.280}{\tan (158.976-90)}=-99.266 \mathrm{~mm}
\end{gathered}
$$

The translation of the $x$ axis can be defined as the diameter $D$ subtracted from the arch rise as given in Eq. (23):

$$
x_{1}=\frac{D}{2}-D \sin \left(\frac{\arcsin \left(\frac{2 y}{D}\right)}{2}\right)^{2}=\frac{0.996}{2}-0.996 \times \sin \left(\frac{\arcsin \left(\frac{2 \times 253.833}{0.996}\right)}{2}\right)^{2}=428.927 \mathrm{~mm}
$$


Table 2: The calculated values (translated coordinates).

\begin{tabular}{|l|c|c|c|c|c|c|}
\hline & $D_{a}$ & $D_{1}$ & $D_{2}$ & $D_{3}$ & $D_{N}$ & Unit \\
\hline$x_{1}$ & 428.927 & 350.746 & 287.075 & 243.297 & 199.159 & {$[\mathrm{~mm}]$} \\
\hline$y_{1}$ & 252.833 & 236.827 & 197.637 & 125.686 & 0.064 & {$[\mathrm{~mm}]$} \\
\hline$z_{1}$ & 112.474 & 133.724 & 156.642 & 181.218 & 185.685 & {$[\mathrm{~mm}]$} \\
\hline$x_{\infty}$ & 497.899 & 423.214 & 348.529 & 273.844 & 199.159 & {$[\mathrm{~mm}]$} \\
\hline$y_{\infty}$ & 0.000 & 0.000 & 0.000 & 0.000 & 0.000 & {$[\mathrm{~mm}]$} \\
\hline$z_{\infty}$ & 0.000 & 0.000 & 0.000 & 0.000 & 0.000 & {$[\mathrm{~mm}]$} \\
\hline$x_{2}$ & 425.670 & 343.460 & 270.985 & 210.505 & 160.360 & {$[\mathrm{~mm}]$} \\
\hline$y_{2}$ & -258.280 & -247.276 & -219.179 & -175.153 & -118.106 & {$[\mathrm{~mm}]$} \\
\hline$z_{2}$ & -99.266 & -113.044 & -124.014 & -130.992 & -133.417 & {$[\mathrm{~mm}]$} \\
\hline
\end{tabular}

The calculated values of the translated coordinates in millimetres are given in Table 2. The $y$ and $z$ values of the coordinates in the middle of the blade are zero as they are the initial values for the shape and thus placed on the $\mathrm{x}$ axis.

\subsection{D model generation}
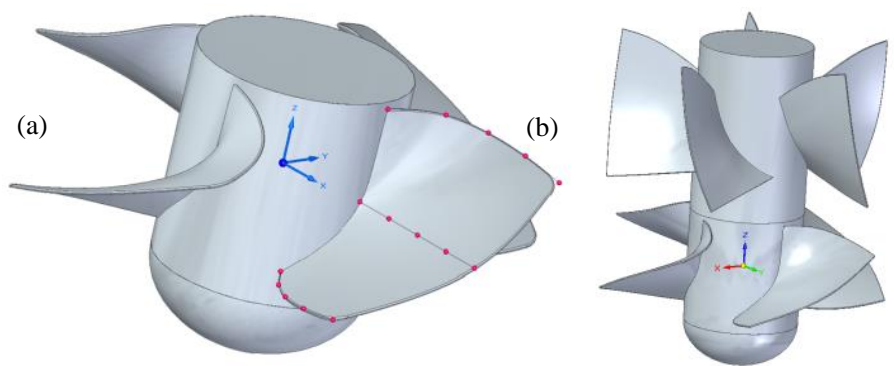

Fig. 9: 3D models: (a) wheel, (b) wheel with guide vanes.

With the information given in Table 2 and the diameter calculations, the shape of the runner blades can now be properly defined. Then, a 3D model was generated in Solid Edge ST6 Academic and is shown in Figure 9-a. The red dots illustrate the calculated coordinates at the inlet, middle and outlet of the blade. Using the face modeller tool in Solid Edge, blade surfaces were created by joining of 15 dots (coordinates at 1, $\infty$ and 2) and the coordinate system is shown in blue on the runner. The use of an aerofoil shape is not possible due to the twisted shape of the blades. The sectional chords vary too much from the inner to outer diameter and hence the blades with $4 \mathrm{~mm}$ constant thickness were considered and this is suitable for the CFD analyses as well. In the analysis, the mechanical structure of the blades will not be considered as this work only concentrates on the fluid flow behaviour for optimizing the shape of the blades.

\subsection{Designing of the guide vanes}

The guide vanes were also designed by following the same principle as the blades and details are given in Table 3 [11]. The final design of the guide vanes and runner is shown in Figure 9-b. The edges of the blades were created in round shape and this will be suitable for the CFD analysis as well.

Table 3: Coordinates of the guide vanes.

\begin{tabular}{|c|c|c|c|c|c|c|}
\hline & $D_{a}$ & $D_{1}$ & $D_{2}$ & $D_{3}$ & $D_{N}$ & Unit \\
\hline$x$ & 481.444 & 399.629 & 316.306 & 231.756 & 147.601 & {$[\mathrm{~mm}]$} \\
\hline$y$ & 126.945 & 139.307 & 146.366 & 145.877 & 133.710 & {$[\mathrm{~mm}]$} \\
\hline$z$ & 296.590 & 276.653 & 239.376 & 187.452 & 124.958 & {$[\mathrm{~mm}]$} \\
\hline$s^{\prime \prime}$ & 0.323 & 0.310 & 0.281 & 0.238 & 0.183 & {$[\mathrm{~mm}]$} \\
\hline
\end{tabular}




\section{CFD analysis}

The theoretically designed runner was analysed with ANSYS for further evaluation and optimisation of the design.

\subsection{CFD solving setup}

First a proper model should be created to define the fluid flow inside the turbine section. The 3D model of the runner and guide vanes (created with Solid Edge) were imported to the ANSYS Design Modeller. Figure 10 shows the structure of the 3D model and the mesh created for CFD analysis. The turbine runner is centred inside the draught tube which is a $2 \mathrm{~m}$ long cylinder for the CFD analysis.

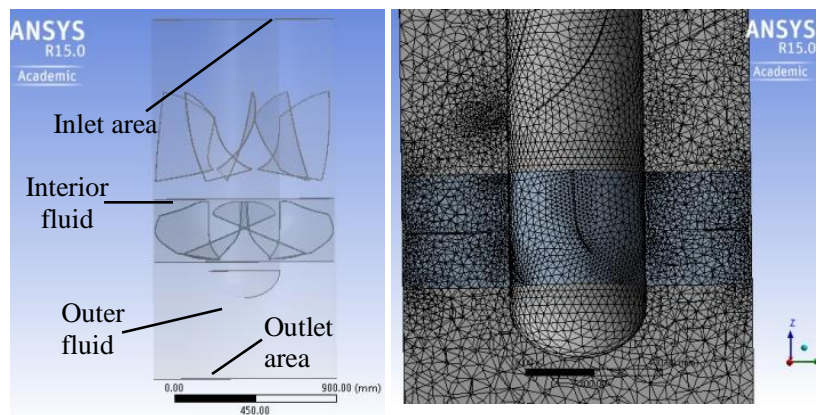

Fig. 10: Left - 3D model of the runner and guide vanes, Right - Mesh created in ANSYS 15.

The fluid model consists of 2 bodies: the outer fluid which contains the static geometry, and the interior fluid which contains the rotating geometry (the runner). This mesh consists of more than 750,000 tetrahedral shaped cells. Tetrahedral shaped elements are necessary for accurate modelling as well as to achieve a low aspect ratio, a high orthogonal ratio and a low skewness ratio (i.e., a comparison ratio between optimal (equilateral) cells and the actual cells) [13]. After confirming the mesh's accuracy, it is necessary to select appropriate settings (e.g., inlet area, outlet area, rotational axis, water density, temperature, flow direction, mesh motion area and speed, calculation approach). The water enters through the inlet with a speed of 7.643 m.s-1 $\left(c_{0}\right)$ and exits through the outlet. The interior fluid which contains inside the runner rotates in counter clockwise about the $\mathrm{z}$ axis and has a rotational speed of $392.25 \mathrm{rpm}$. For the evaluation, the laminar $\mathrm{k}$ epsilon equations were used.

\subsection{Limitations}

After the first few trials in ANSYS-Fluent, some of the limitations were observed which might have some impacts on the optimisation process. The issue was that ANSYS showed some limitations of viewing results of moving solid objects (i.e., the runner in this case). The possible solution was the creation of a cylinder around the moving geometry (runner) and subtracts the solid body from the cylinder volume so that only the fluid geometry of the runner is left [14]. This volume of the fluid around the runner is then defined as the interior fluid which is now able to rotate for the calculation process (see Figure 10). Due to this issue, the flow behaviour with streamlines and turbulences can hardly be analysed. Previous work by Technical University Graz [15] has used the same method for optimisation of a Kaplan turbine where the results were accurate enough to implement modifications. In general, the smaller the clearance between the cylinder drawn and the runner the higher the accuracy is. However, tight clearance between the cylinder and runner may affect the mesh quality. The right adjustment was determined with the procedures explained by ANSYS [14].

\section{Results and Discussion}

\subsection{Optimization of the runner wheel with CFD}

The original theoretically designed runner with 4 blades showed only 50.98\% of efficiency in ANSYS. Hence, it was optimized with CFD by adjusting the blades to achieve a higher tangential velocity difference $\Delta w_{u}$ which would help to achieve a better efficiency. At first, the effects of the number of blades on the runner's efficiency were evaluated. With ANSYS, the tangential velocities of the inlet and outlet edges of the runner ( $c_{u 1}$ and $c_{u 2}$ ) were checked when the number 
of blades increased from 3 to 7 . Here, the mass flow rate $\dot{m}$ and tangential velocity of the blades $u$ were kept the same and the corresponding results are presented in Table 4.

Table 4: Details of the theoretical design with 3-7 blades.

\begin{tabular}{|c|c|c|c|c|c|c|}
\hline & 3 Blades & 4 Blades & 5 Blades & 6 Blades & 7 Blades & Unit \\
\hline$c_{u 1}$ & 4.122 & 4.14362 & 4.283 & 4.203 & 4.167 & {$[\mathrm{~m} / \mathrm{s}]$} \\
\hline$c_{u 2}$ & 2.813 & 2.04766 & 1.712 & 1.563 & 1.569 & {$[\mathrm{~m} / \mathrm{s}]$} \\
\hline$\Delta w_{u}$ & 1.309 & 2.09596 & 2.571 & 2.64 & 2.598 & {$[\mathrm{~m} / \mathrm{s}]$} \\
\hline$P_{\text {runner }}$ & 93607.3 & 149883.2 & 183853.6 & 188787.8 & 185784.4 & {$[\mathrm{~W}]$} \\
\hline$\eta_{r}$ & 31.84 & 50.98 & 62.53 & 64.21 & 63.19 & {$[\%]$} \\
\hline
\end{tabular}

It is clear that the number of blades affects the efficiency. The highest efficiency was achieved as $64.21 \%$ with 6 blades. However, Menny [4] stated that the highest efficiency should be achieved with 4 blades for this type of turbines. Then, the inlet velocity $c_{0}$ of the draught tube was analysed. The inlet velocity depends on the water flow rate through the runner. As more water enters the turbine section, the flow rate $\dot{V}$ increases due to the constant diameter of the draught tube and hence the inlet velocity also increases. As was calculated before, the inlet velocity $c_{0}$ was achieved as $7.643 \mathrm{~m} . \mathrm{s}^{-1}$. With ANSYS, the inlet velocity can also be changed to investigate its impact on the tangential velocity difference of the water and the results are shown in Figure 11. Then, Figure 12 represents the trend of the increasing power output with the increasing inlet velocity $c_{0}$. As evident, the power output increases rapidly from an inlet velocity of $6.5 \mathrm{~m} . \mathrm{s}^{-1}$ to $7.64 \mathrm{~m} . \mathrm{s}^{-1}$ and then the rate of increase decreases. As evident, the power output increases rapidly from an inlet velocity of $6.5 \mathrm{~m} . \mathrm{s}^{-1}$ to $7.64 \mathrm{~m} . \mathrm{s}^{-1}$ and then the rate of increase decreases. As shown in Figure 13, the efficiency of the runner is not increasing as the inlet velocity increases and it comes to a maximum of around 51.5\% at an inlet velocity between 7.64-8.0 m.s. $\mathrm{s}^{-1}$, and then starts to decrease. As the changes of the number of blades and inlet velocity were not that effective, then it was attempted optimize the blades to improve the efficiency by following a similar methods to Bashir et al [9]. Here, theoretically defined inlet angle $\beta_{1}$ and outlet angle $\beta_{2}$ were analysed which define the shape of the blades and these influence the power output as well. Styrylski et al. [16] stated that a high pressure situation usually occurs on the top blade surface (in the rotational direction) than the bottom surface. The pressure difference between the top and bottom surfaces affects the rotational movement and hence the power output of the runner. Here, the optimisation of the blade shape (by changing $\beta_{1}$ and $\beta_{2}$ ) with ANSYS was executed in 9 steps and the results are given in Table 5. The highest efficiency achieved was $93.01 \%$ and this design is called the optimized design here onward. Then, another check was carried out with the optimized design to check the effects of number of blades (see Figure 14). Regardless the previously obtained results given in Table 4, the highest efficient runner was obtained with 4 blades and this agrees with the previously reported findings [4] as well.

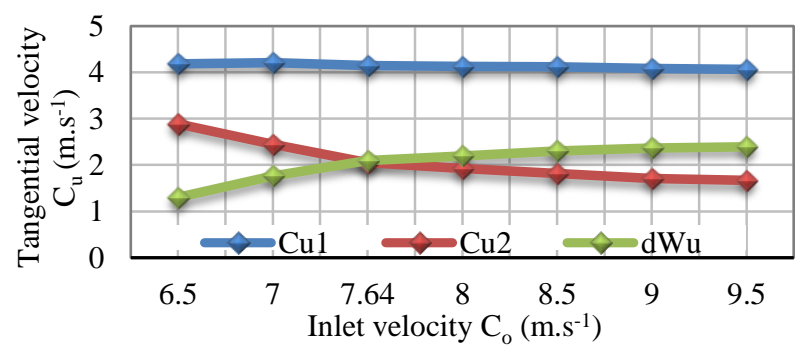

Fig. 11: Tangential velocity $C_{u}$ vs inlet velocity $C_{o}$. 


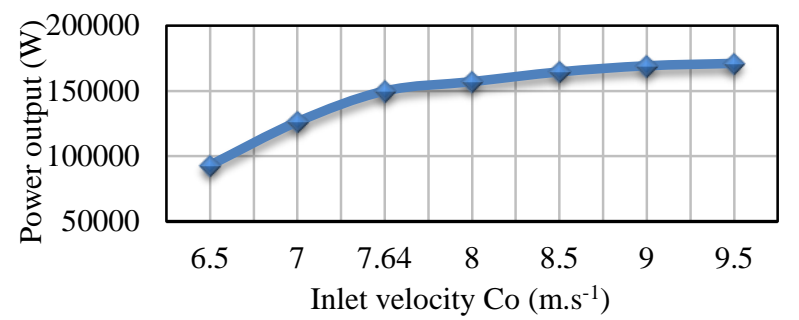

Fig. 12: Power output with different inlet velocities $\mathrm{C}_{\mathrm{o}}$

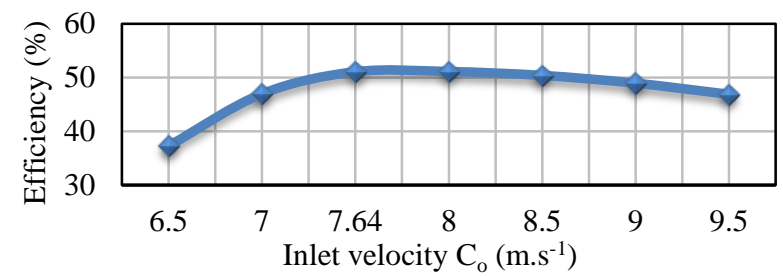

Fig. 13: Efficiency vs inlet velocity $\mathrm{C}_{\mathrm{o}}$

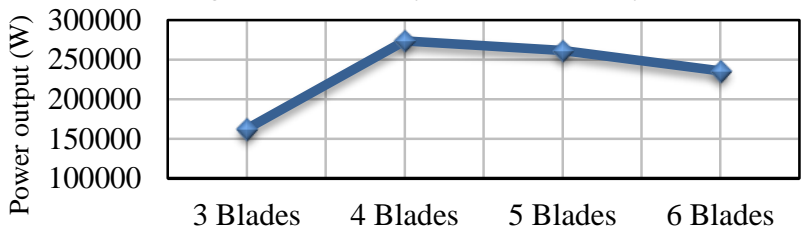

Fig. 14: The optimized runner's power output.

Table 5: Results of the optimisation steps.

\begin{tabular}{|c|c|c|c|c|c|c|c|c|c|c|}
\hline & Mod.1 & Mod.2 & Mod.3 & Mod.4 & Mod.5 & Mod.6 & Mod.7 & Mod.8 & Mod.9 & Unit \\
\hline$c_{u 1}$ & 4.215 & 4.006 & 3.979 & 3.981 & 4.104 & 4.191 & 4.351 & 4.241 & 4.286 & {$[\mathrm{~m} / \mathrm{s}]$} \\
\hline$c_{u 2}$ & 2.018 & 0.975 & 0.533 & 0.768 & 0.545 & 0.539 & 0.527 & 0.577 & 0.581 & {$[\mathrm{~m} / \mathrm{s}]$} \\
\hline$\Delta w_{u}$ & 2.197 & 3.031 & 3.446 & 3.213 & 3.559 & 3.652 & 3.824 & 3.664 & 3.705 & {$[\mathrm{~m} / \mathrm{s}]$} \\
\hline$P_{\text {runner }}$ & 160250.8 & 216748.4 & 246425.3 & 229763.3 & 254506.0 & 261156.5 & 273456.3 & 262014.6 & 264946.5 & {$[\mathrm{~W}]$} \\
\hline$\eta_{r}$ & 54.51 & 73.72 & 83.82 & 78.15 & 86.56 & 88.83 & 93.01 & 89.12 & 90.12 & {$[\%]$} \\
\hline
\end{tabular}

\subsection{Comparison of theoretical and CFD optimized designs}

\section{Tangential Velocity}

As shown in Figure 16, the tangential velocity affects the power output and hence the efficiency of the runner as well. The theoretical and CFD tangential inlet/outlet velocities follow the same trend but the theoretical magnitudes are higher than that of the CFD. The tangential velocity difference $\Delta w_{u}$ of the theoretical, CFD and CFD optimized designs are 3.865 $\mathrm{m} . \mathrm{s}^{-1}, 2.096 \mathrm{~m} . \mathrm{s}^{-1}$ and $3.824 \mathrm{~m} . \mathrm{s}^{-1}$, respectively.

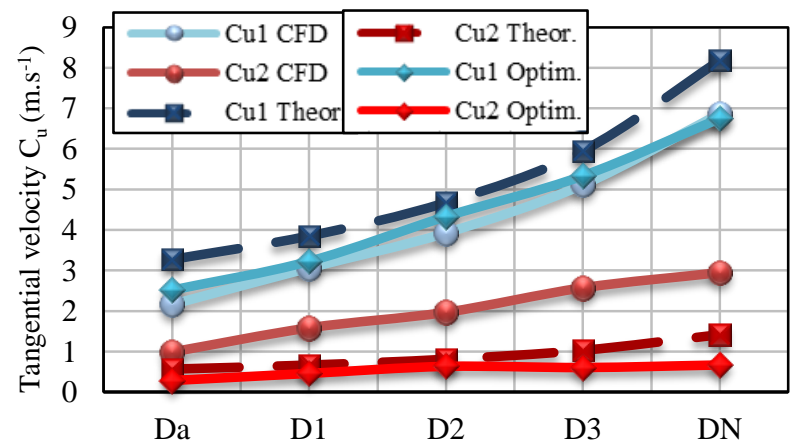

Fig. 15: Tangential velocities at different diameters: Theoretical, CFD theoretical and CFD optimized designs. 


\section{Power output and efficiency}

With the increase of the tangential velocity difference $\Delta w_{u}$, the new power output of the runner $P_{\text {runner }}$ is given as:

$$
\begin{gathered}
P_{\text {runner }}=\rho \frac{1}{4} \pi\left(D_{a}{ }^{2}-D_{N}{ }^{2}\right) c_{0} u \Delta w_{u} \\
P_{\text {runner }}=999 \times 0.25 \pi\left(0,9958^{2}-0.3983^{2}\right) \times 7.643 \times 14.316 \times 3.824=273,456.3 \mathrm{~W}
\end{gathered}
$$

With the optimised runner's power output and the total power provided by the water $(294005.7 \mathrm{~W})$, the new efficiency of the CFD optimized design can be obtained:

$$
\eta_{r}=\frac{P_{\text {runner }}}{P_{\text {water }}} \times 100 \% \quad=\frac{273456.3}{294005.7} \times 100 \% \quad=93.01 \%
$$

The theoretically calculated power output was $276365.36 \mathrm{~W}$ whereas the power output provided by the CFD for the same design was $149883.2 \mathrm{~W}$ while the CFD optimized design provided $273456.3 \mathrm{~W}$. The water provides a constant power output of 294,007.7 W for a water stream with $6 \mathrm{~m}$ of head and a flow rate of $5 \mathrm{~m}^{3} . \mathrm{s}^{-1}$. Hence, by the CFD optimization carried out so far, the efficiency of the runner $\eta_{r}$ has been increased from $50.98 \%$ to $93.01 \%$. Furthermore, the power output of the optimized design with the flow rate changes (inlet velocity) was observed and shown in Figure 16-a. It is obvious that the power output increases with the increasing inlet velocity. The corresponding efficiency values were also determined and shown in Figure 16-b.
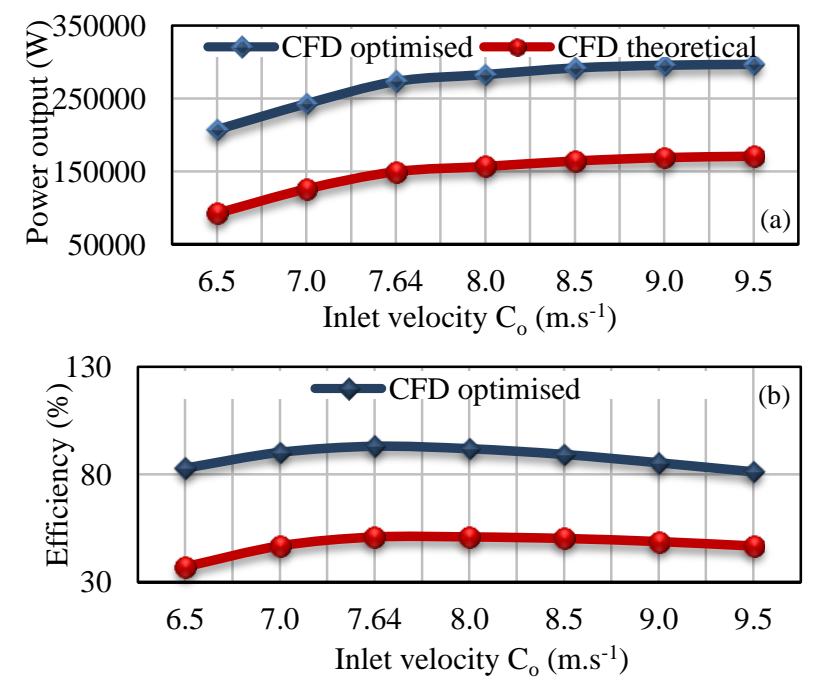

Fig. 16: The expected power output (top) efficiency (bottom) of the original and optimized runners with the changes of the inlet velocity.

Although the power output increases with the inlet velocity the efficiency of the runner reaches a maximum of $93.01 \%$ with an inlet velocity of $7.64 \mathrm{~m} . \mathrm{s}^{-1}$ and then starts to decrease. The original theoretical design in CFD shows a maximum efficiency of about $51-52 \%$ (exactly $50.98 \%$ ), somewhere between 7.64 and $8 \mathrm{~m} . \mathrm{s}^{-1}$. However, the theoretical calculations provided an efficiency of $94 \%$. There could be several reasons to have such differences between theoretical and CFD results. According to the previous works $[3,4,17]$, the theoretical designs are mostly for achieving an approximate design only. Many of the theoretical equations are based on several assumptions that would lead to accuracy problems. As they mentioned, the theoretically designed runners always need to be evaluated and developed with software packages such as CFD for achieving the optimum performance. However, the designs performed with CFD would also have varying degrees of accuracy depending on the issues such as the quality of the mesh and the calculation method used [9, 18, 19]. Moreover, the draught tube and the runner shaft should also be considered for proper optimization of a turbine. Although the geometries of the draught tube and the runner shaft would not influence the theoretical efficiency [4, 6, 17, 20, 21], the CFD analyses would be influenced by them when defining boundary conditions. Additionally, the tangential velocities 
provided by CFD may also slightly be inaccurate due to the limited shaping of measurement planes. The planes for the surface integral measurements at the blades' inlet and outlet were not exactly on the actual inlet and outlet edges because these can only be inserted as even planes. Thus, the planes were inserted as close as possible to the inlet and outlet edges.

\section{Flow behaviour}

The flow behaviour across the CFD optimized design was also observed and shown in Figure 17. A clear difference in flow behaviour is visible between both designs. However, the difference of the flow behaviour inside the runner section cannot be seen due to the graphic rendition of a moving geometry with ANSYS as was explained before. The water leaves quite straight through the draught tube of the optimised runner whereas a more swirl flow behaviour is observable from the theoretical design. Hence, the water leaving from the theoretical runner still has some potential in generating power [4]. In other words, theoretical design is not capable of extracting energy of the flowing water effectively as good as the optimized design.

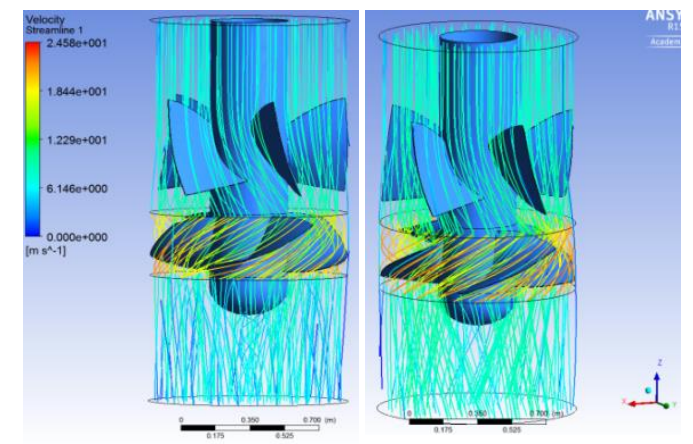

Fig. 17: Velocity stream lines: Left - Optimized design, Right - Theoretical design.

\section{Pressure distribution}

The pressure distribution across the runner before and after the optimisation is illustrated in Figure 18. As shown by the index bar, the maximum pressure of the optimised runner has increased from $160 \mathrm{~Pa}$ to $184 \mathrm{~Pa}$ and the minimum pressure from -63.8 $\mathrm{Pa}$ to 2.06 $\mathrm{Pa}$. From the colour map, it is noticeable that the pressure on the bottom side of the runner has slightly dropped due to the optimisation. This would lead to have a higher pressure force in rotational direction causing to increases the power output and efficiency [22]. In the theoretical design (top), the back side of the blade (position 1) shows a higher pressure while the front face has a lower pressure (position 2). However, in the optimized design, the pressure on the area marked by position 1 is lower which leads to an improvement of the efficiency. At the $8^{\text {th }}$ step of the blade angles' optimisation, it was tried to further reduce the pressure at this spot by increasing the inlet angle of the blade. However, the tangential velocity difference slightly increased with the increase of the inlet angle but no improvement was noticed in the efficiency. The area of the lowest pressure has also changed with the optimization (position 2) and this area is at a high risk for cavitation which is one of the common problems with fluids based machineries. Hence, the pressure distribution across the blade was analysed to investigate the critical areas if the pressure was below the vapour pressure. If the minimum pressure on the runner wheel is below the vapour pressure it can be assumed that the water is converting into steam so that cavitation occurs and would damage the wheel particularly over the critical area/s. In this work, the maximum temperature and the vapour pressure of the water are defined to be $15^{\circ} \mathrm{C}$ and $1279 \mathrm{~Pa}$, respectively [23]. The lowest pressure over the optimized runner can be noted as $2060 \mathrm{~Pa}$ which is higher than the vapour pressure at $15^{\circ} \mathrm{C}$ and hence it can be assumed that there is no risk of occurring cavitation. In this work, the critical areas of the low pressure (shown in blue) are exactly on the same spots as was observed by Mecaflux [24] in his work. 


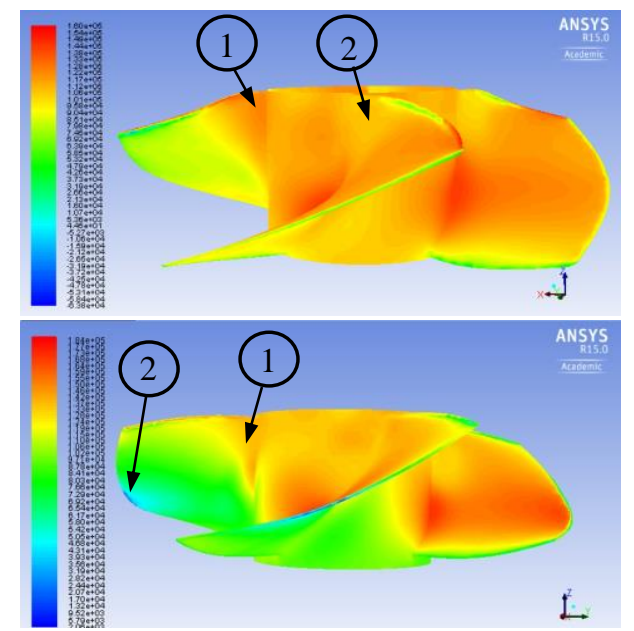

Fig. 18: Pressure distribution across the runner wheel: Top - before optimization, Bottom - after optimization.

\section{Conclusions}

A Kaplan runner wheel was theoretically designed to reach an efficiency of $94 \%$. However, the CFD analyses showed that the same theoretical design only has an efficiency of 50.98\%. Here, it can be argued that the theoretical design is low in accuracy particularly due to the numerous simplifying assumptions attached with the calculation process. However, such theoretical calculations should be good to have an approximate design. Therefore, the theoretical design was optimized with ANSYS for developing an efficient runner wheel. With the CFD analysis, it was possible to adjust the design parameters of the blades to improve the efficiency of the runner from 50.98\% to $93.01 \%$. The CFD results showed that the number of blades on the wheel and the size of the blades' inlet and outlet angles would influence the tangential velocity difference between the blades' inlet and outlet which showed a major impact on the turbine's efficiency. As was observed, the higher the tangential velocity difference between the blades' inlet and outlet the higher the power output is and hence the efficiency. The efficiency of the theoretically designed runner increased slightly as increasing the number of blades. However, increasing of number of blades is always not possible and there should be a maximum possible number of blades for a particular size of a wheel. Also, this will lead to more complexities in the design process (leading to cost increments as well) and hence would not be a better way of increasing the efficiency. A significant impact on the turbine's efficiency was achieved by modifying of the blades' inlet and outlet angles where an increase of up to $42.03 \%$ could be achieved in this study.

\section{References}

[1] H. Moller, Data highlights: Hydropower continuous steady growth, [Online]. Available: http://www.earthpolicy.org/data_highlights/2012/highlights29

[2] International Energy Agency, [Online]. Available: https://www.iea.org/topics/renewables/subtopics/hydropower/

[3] M. Woehl, The Kaplan Turbine - a Hydropower Innovation Celebrates its 100th Birthday, Voith GmbH, Heidenheim in Germany, [Online]. Available: http://www.voith.com/en/press/press-releases-99_49042.html

[4] K. Menny, Strömungsmaschinen - Hydraulische und thermische Kraft- und Arbeitsmaschinen, Verlag, Ronnenberg, Germany, 2006.

[5] Power-technology, the 10 biggest hydroelectric power plants in the world, London UK, [Online]. Available: http://www.power-technology.com/features/feature-the-10-biggest-hydroelectric-power-plants-in-the-world

[6] S. L. Dixon, Fluid Mechanics, and Thermodynamics of Turbomachinery, $5^{\text {th }}$ Edition, Elsevier ButterworthHeinemann, 2005.

[7] US Dept. of Energy, History of Hydropower, Washington, [Online]. Available: http://energy.gov/eere/water/historyhydropower

[8] RDT, 20014, Kraft- und Arbeitsmaschinen Skript, Rudolf Diesel Technikum Augsburg in Germany. 
[9] J. A. Bashir, K. Shahid and S. Muhammad, "Blade Profile Optimisation of Kaplan Turbine Using CFD Analysis," J. of Eng. \& Technology, Mehran University, Pakistan, 2012.

[10] J. Dragica, A. Škerlavaj, L.Andrej, "Improvement of Efficiency Prediction for a Kaplan Turbine with Advanced Turbulence Models," Turboinštitut, Journal of Mechanical Engineering, Slovenia, 2014.

[11] PACER, Kleinwasserkraftwerke, Wasserturbinen, Switzerland, 1995.

[12] T. Flaspöhler, "Design of the runner of a Kaplan turbine for small hydroelectric power plants," Tampere Uni. of Applied Sciences, Tampere, Finland, 2007.

[13] H. Choi, M. Zullah, H. Roh, P. Ha, S. Oh, and Y. Lee, "CFD validation of performance improvement of a 500kW Francis turbine," Renewable Energy, vol. 54, pp. 111-123, 2013.

[14] ANSYS, Canonsburg, Pennsylvania, USA, 2015, [Online]. Available: http://www.ansys.com

[15] Institute for Hydraulic Fluid Machinery, Entwicklung einer Kaplan-Rohrturbinen-Hydraulik, Technical University Graz, Graz in Austria, 2012, [Online]. Available: http://www.hfm.tugraz.at/de/referenzen/turbine/entwicklung-einerkaplan-rohrturbinen-hydraulik.html> [Last Viewed: 08/04/2014].

[16] M. Styrylski, J. Tomalik and M. M. Grahl, "Computer Aided Engineering as a Useful Tool in Hydraulic Turbine Design," Krzeszowice, Poland, 2009.

[17] ESHA \& Penche Celso, Guide on How to Develop a Small Hydropower Plant, TNSHP, Brussels, Belgium, 2004.

[18] J. Dragica, A. Škerlavaj and L.Andrej, "Improvement of Efficiency Prediction for a Kaplan Turbine with Advanced Turbulence Models," Turboinštitut, Journal of Mechanical Engineering, Slovenia, 2014.

[19] M. Lukas, S. Ales and O. Jiri, "Conditions of Kaplan Turine CFD Analysis," CKD Blansko Engineering, Blansko, Czech Republic, 2010.

[20] F. Loiseau, "Importance of draft tube in rehabilitation projects," LAHR $24^{\text {th }}$ Symposium on Hydraulic Machinery and Systems, Foz do Iguazzu, Brazil, 2008.

[21] C. T. Vu, M. Gauthier, B. Nennemann, H. Wallimann and C. Deschênes, "CFD analysis of a blub turbine and validation with measurements from the BlubT project," IAHR 2014, Canada and Switzerland, 2013.

[22] M. Styrylski, J. Tomalik, and M. M. Grahl, "Computer Aided Engineering as a Useful Tool in Hydraulic Turbine Design," Krzeszowice in Poland, 2009.

[23] Nave Rod, Saturated Vapor Pressure, Density of Water Hyper Physics, Guelph, Canada, 2000, [Online]. Available: http://hyperphysics.phy-astr.gsu.edu/hbase/kinetic/watvap.html

[24] Mecaflux, Cavitation propeller and hydrofoils or foils, Mecaflux Heliciel, Naves, France, 2013, [Online]. Available: http://www.heliciel.com/en/aerodynamique-hydrodynamique/cavitation-\%20helices-hydrofoils.htm

\section{Nomenclature}

$\begin{array}{lll}\text { Symbol Description } & \text { Unit } \\ A & \text { Sectional area of draught tube } & {\left[\mathrm{m}^{2}\right]} \\ c & \text { Velocity of fluid flow } & {[\mathrm{m} / \mathrm{s}]} \\ c_{u 2} & \text { Tangential inlet velocity } & {[\mathrm{m} / \mathrm{s}]} \\ c_{u 1} & \text { Tangential outlet velocity } & {[\mathrm{m} / \mathrm{s}]} \\ D_{a} & \text { Runner diameter } & {[\mathrm{m}]} \\ D_{N} & \text { Hub diameter } & {[\mathrm{m}]} \\ F_{m} & \text { Meridian force } & {[\mathrm{N}]} \\ F_{r e s} & \text { Resulting force } & {[\mathrm{N}]} \\ F_{u} & \text { Tangential force } & {[\mathrm{N}]} \\ g & \text { Acceleration of gravity } & {\left[\mathrm{m} / \mathrm{s}^{2}\right]} \\ H & \text { Head } & {[\mathrm{m}]} \\ H_{s} & \text { Suction head } & {[\mathrm{m}]} \\ H_{S m a x} & \text { Maximum suction head } & {[\mathrm{m}]}\end{array}$

$\begin{array}{lll}\text { Symbol Description } & \text { Unit } \\ M & \text { Torque } & {[\mathrm{Nm}]} \\ \dot{m} & \text { Mass flow rate } & {[\mathrm{kg} / \mathrm{s}]} \\ n & \text { Speed, Drive } & {\left[\mathrm{s}^{-1}\right]} \\ n_{q n} & \text { Specific speed } & {[-]} \\ P & \text { Power } & {[\mathrm{Watt}]} \\ p & \text { Pressure } & {[\mathrm{Pa}]} \\ p_{a t m} & \text { Atmospheric pressure } & {[\mathrm{Pa}]} \\ p_{v} & \text { Vapour pressure of water } & {[\mathrm{Pa}]} \\ s^{\prime \prime} & \text { Chord length } & {[\mathrm{m}]} \\ t^{\prime \prime} & \text { Blade partition } & {[\mathrm{m}]} \\ u & \text { Tangential velocity } & {[\mathrm{m} / \mathrm{s}]} \\ \dot{V} & \text { Flow rate (also discharge) } & {\left[\mathrm{m}^{3} / \mathrm{s}\right]} \\ w & \text { Relative velocity } & {[\mathrm{m} / \mathrm{s}]}\end{array}$

$\begin{array}{ll}\text { Symbol Description } \\ w & \text { Relative velocity } \\ x & \text { Coordinate value, x-direction } \\ y & \text { Coordinate value, y-direction } \\ z & \text { Coordinate value, z-direction } \\ z " & \text { Number of Blades } \\ \alpha & \text { Angle of attack } \\ \beta & \text { Angle of velocity flow } \\ \Delta & \text { Difference } \\ \delta & \text { Diameter number } \\ \eta & \text { Efficiency } \\ \sigma & \text { "Schnelläufigkeit" } \\ \sigma_{c} & \text { Cavitation coefficient } \\ \rho & \text { Density of water }\end{array}$

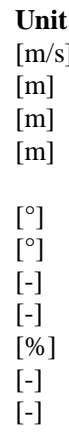

